TITLE:

\title{
Structure of the human M2 muscarinic acetylcholine receptor bound to an antagonist
}

\section{AUTHOR(S):}

Haga, Kazuko; Kruse, Andrew C.; Asada, Hidetsugu; YurugiKobayashi, Takami; Shiroishi, Mitsunori; Zhang, Cheng; Weis, William I.; ... Kobilka, Brian K.; Haga, Tatsuya; Kobayashi, Takuya

\section{CITATION:}

Haga, Kazuko ...[et al]. Structure of the human M2 muscarinic acetylcholine receptor bound to an antagonist. Nature 2012, 482(7386): 547-551

\section{ISSUE DATE:}

2012-01-25

URL:

http://hdl.handle.net/2433/152410

\section{RIGHT:}

C2012 Macmillan Publishers Limited. All rights reserved; 許諾条件によ り本文は2012-07-25に公開.; この論文は出版社版でありません。引用 の際には出版社版をご確認ご利用ください。; This is not the published version. Please cite only the published version. 


\section{Structure of the human $\mathbf{M}_{2}$ muscarinic acetylcholine receptor bound to an antagonist}

Kazuko Haga ${ }^{1 *}$, Andrew C. Kruse ${ }^{2 *}$, Hidetsugu Asada ${ }^{3,4 *}$, Takami Yurugi-Kobayashi $^{3,4}$, Mitsunori Shiroishi ${ }^{4,5}$, Cheng Zhang ${ }^{2}$, William I. Weis ${ }^{2,6}$, Tetsuji Okada ${ }^{1}$, Brian K. Kobilka ${ }^{2}$, Tatsuya Haga ${ }^{1}, \&$ Takuya Kobayashi ${ }^{3,4}$

${ }^{1}$ Department of Life Science, Faculty of Science, Gakushuin University, Mejiro 1-5-1, Tokyo 171-8588, Japan, ${ }^{2}$ Department of Molecular and Cellular Physiology, Stanford University School of Medicine, 279 Campus Drive, Stanford, California 94305, USA, ${ }^{3}$ Department of Medical Chemistry and Cell Biology, Kyoto University Faculty of Medicine, Konoe-cho, Yoshdida, Sakyo-Ku, Kyoto 606-8501, Japan, ${ }^{4}$ Human Receptor Crystallography Project, ERATO, Japan Science and Technology Agency, Konoe-cho, Yoshida, Sakyo-Ku, Kyoto 606-8501, Japan, ${ }^{5}$ Graduate School of Pharmaceutical Sciences, Kyushu University, 3-1-1 Maidashi, Higashi-ku, Fukuoka 812-8582, Japan, ${ }^{6}$ Department of Structural Biology, Stanford University School of Medicine, 299 Campus Drive, Stanford, California 94305, USA

*These authors contributed equally to this work.

The parasympathetic limb of the autonomic nervous system regulates the activity of multiple organ systems. Muscarinic receptors are $\mathrm{G}$ protein coupled receptors (GPCRs) that mediate the response to acetylcholine released from parasympathetic nerves. Their role in the unconscious regulation of organ and central nervous system function makes them potential therapeutic targets for a broad spectrum of diseases. The $M_{2}$ muscarinic acetylcholine receptor $\left(M_{2}\right.$ receptor) is essential for the physiologic control of cardiovascular function through activation of $\mathrm{G}$ protein-coupled inwardly-rectifying potassium channels, and is of particular interest because of its extensive pharmacological characterization with both orthosteric and allosteric ligands. Here we report the 
structure of antagonist-bound $\mathrm{M}_{2}$ receptor, the first human acetylcholine receptor to be characterized structurally. The antagonist QNB binds in the middle of a long aqueous channel extending approximately two-thirds through the membrane. The orthosteric binding pocket is formed by amino acids that are identical in all 5 muscarinic receptor subtypes, and shares structural homology with other functionally unrelated acetylcholine binding proteins from different species. A layer of tyrosine residues forms an aromatic cap restricting dissociation of the bound ligand. A binding site for allosteric ligands has been mapped to residues at the entrance to the binding pocket near this aromatic cap. The $M_{2}$ receptor structure provides insights into the challenges of developing subtype-selective ligands for muscarinic receptors and their propensity for allosteric regulation. 
The muscarinic receptors constitute a family with five subtypes $M_{1}-M_{5}{ }^{1} . M_{1}, M_{3}$, and $M_{5}$ subtypes couple with the $G q$ family of $G$ proteins, and $M_{2}$ and $M_{4}$ subtypes with the Gi/Go family of $G$ proteins. The muscarinic acetylcholine receptors were originally defined as a functional concept on the basis of the work by Dale $^{2}$ and others showing that the muscarinic action by a series of choline esters and other substances in various tissues could be differentiated from their nicotinic action. The muscarinic receptors are now known to be $\mathrm{G}$ proteincoupled receptors (GPCRs) ${ }^{3}$ and the nicotinic receptor a ligand-gated ion channel. Muscarinic receptors were initially defined biochemically as proteins that specifically bound 3-quinuclidinyl-benzilate (QNB) and N-methylscopolamine (NMS). They were among the first GPCRs to be purified from cerebral membranes ${ }^{4}$, and to be functionally reconstituted with purified $G$ protein in lipid vesicles $^{3}$. The $M_{1}$ receptor $^{5}$ together with the $\beta_{2}$ adrenergic receptor ${ }^{6}$ were the first neurotransmitter-activated GPCRs to be cloned, revealing the seven transmembrane segment (TM) topology initially observed for rhodopsin ${ }^{7}$, and subsequently found to be common to all members of the GPCR family.

As a consequence of their roles in both the central and parasympathetic nervous systems, muscarinic receptors are targets for treatment of a spectrum of disorders including Alzheimer's disease, schizophrenia and Parkinson's disease, and chronic obstructive pulmonary disease ${ }^{8}$. However, developing highly subtype selective orthosteric drugs for muscarinic receptors has been challenging and thus far largely unsuccessful. Recent drug discovery efforts have therefore shifted to the development of small molecule allosteric modulators. Muscarinic receptors have long been a model system for studying allosteric regulation of GPCR signaling because of their exceptional propensity to bind allosteric ligands ${ }^{9}$. To better understand the structural basis for challenges in developing orthosteric drugs and the susceptibility for allosteric regulation, we obtained a crystal structure of the $\mathrm{M}_{2}$ receptor.

In our initial efforts to obtain the structure of the $M_{2}$ receptor we expressed and 
purified $M_{2}$ receptor lacking most of the third intracellular loop (IL3) and the native glycosylation sites. The central part of IL3 of the $M_{2}$ receptor can be removed without impairing its ability to bind to agonists or activate $G$ proteins ${ }^{10}$, and IL3 was shown to have a flexible structure ${ }^{11}$. Using this modified $\mathrm{M}_{2}$ receptor bound to the high affinity inverse agonist R-(-)-3-QNB, we performed crystallization by hanging drop vapor diffusion and obtained crystals that diffracted to around $9 \AA$, but were not able to improve the quality of these crystals. We subsequently replaced IL3 of the $M_{2}$ receptor with T4-Lysozyme (T4L) as initially described for the $\beta_{2}$ adrenergic receptor ${ }^{12}$ (Supplementary Fig. 1a). This method has been used to obtain crystal structures of four other GPCRs: the adenosine $A_{2 A}$ receptor ${ }^{13}$, the CXCR4 receptor $^{14}$, the dopamine receptor $\mathrm{D} 3^{15}$, and most recently the histamine $\mathrm{H}_{1}$ receptor $^{16}$. The binding properties of $M_{2}-T 4 L$ with muscarinic ligands were essentially the same as for the wild type $M_{2}$ receptor (Supplementary Fig. 1b,c), indicating that the overall TM architecture of $M_{2}-T 4 L$ was minimally affected by introduction of $T 4 L$. The $M_{2}-T 4 L$ was subsequently crystallized in lipidic cubic phase. A $3.0 \AA$ structure was solved by molecular replacement from a data set obtained by merging diffraction data from 23 crystals.

As is typical for proteins crystallized by the lipidic cubic phase method, the lattice for the $M_{2}$ receptor shows alternating aqueous and lipidic layers with $M_{2}$ receptor molecules embedded in the latter while $\mathrm{T} 4 \mathrm{~L}$ is confined to aqueous regions (Supplementary Fig. 2). Within the membrane plane, receptor molecules are packed closely against one another, alternating orientations within the bilayer. There are abundant hydrophobic contacts between receptor molecules within the membrane, while polar interactions primarily involve contacts between T4L molecules as well as receptor-T4L interactions.

The overall structure of the $M_{2}$ receptor (Fig. 1a) is similar to that of rhodopsin and other recently crystallized inactive GPCR structures (compared in Supplementary Figure 3). The cytoplasmic surface of the $M_{2}$ receptor is in an 
inactive conformation, but as with most other GPCR structures, there is no interaction involving Arg1213.50 in the conserved E/DRY sequence in TM3 and Glu382 $2^{6.30}$ in TM6 (Fig. 1b). Instead, the Arg121 $1^{3.50}$ side chain forms a salt bridge only with Asp $120^{3.49}$. In rhodopsin, the homologous residues form part of a charge-charge interaction that stabilizes the cytoplasmic ends of TM3 and TM6 in an inactive state ${ }^{17}$. The second intracellular loop shows a helical conformation similar to that first seen for the turkey $\beta_{1}$ adrenergic receptor ${ }^{18}$.

GPCR crystal structures show the greatest differences in the extracellular surface (Supplementary Fig. 3). The $\mathrm{M}_{2}$ receptor has a relatively simple and open extracellular surface (Fig 1c, d) with the longer extracellular loop (ECL) 2 stabilized by a conserved disulfide with Cys $96^{3.25}$ at the $\mathrm{N}$-terminus of TM3 and Cys176 in the middle of ECL2. In addition, the second disulfide bond was detected between C413 and C416 in the ECL3. The extracellular surface of the $M_{2}$ receptor most resembles that of the dopamine D3 receptor (Supplementary Fig. 3).

Crystal structures of GPCRs reveal a network of hydrogen bonding interactions that extend from the binding pocket to the cytoplasmic surface. However, a distinctive feature of the $M_{2}$ receptor is that this network is part of a long, continuous aqueous channel extending from the extracellular surface to a depth of approximately $33 \AA$ when measured from ECL2 (Fig 1e). This channel contains the ligand binding pocket, but extends beyond the ligand and is separated from the cytoplasmic surface by a hydrophobic layer formed by three amino acids: Leu65 $5^{2.46}$ in TM2, Leu114 $4^{4.43}$ in TM4 and Ile392 ${ }^{6.40}$ in TM6. Each of these is absolutely conserved among all five muscarinic subtypes. The dimensions of the channel below the QNB binding site are large enough to accommodate a long, extended orthosteric ligand. Supplementary Figure 4 compares the aqueous channels of other GPCRs.

The ligand QNB binds within a deeply buried pocket defined by side chains of 
TM3, 4, 5, 6 and 7 (Fig. 2a-c, Supplementary Fig. 5, Supplementary table 3). An aromatic cage encloses the amine and forms a lid over the ligand, separating the orthosteric site from the extracellular vestibule. Asp $103^{3.32}$ and Asn404 $4^{6.52}$ serve to orient the ligand in the largely hydrophobic binding cavity, with Asn404 ${ }^{6.52}$ forming paired hydrogen bonds with the hydroxyl and carbonyl groups in QNB while Asp $103^{3.32}$ engages in a charge-charge interaction with the amine moiety of the ligand (Fig. 2). The transmembrane segment amino acids that form the QNB binding pocket are identical in all five muscarinic receptor subtypes (Supplementary Table 1), consistent with results of QNB binding experiments on $M_{1}-M_{4}$ receptors, and with site-directed mutagenesis experiments on $M_{1}{ }^{19}, M_{2}{ }^{20}$, and $\mathrm{M}_{3}{ }^{21}$ receptors. Only Phe181, which extends downward from ECL2 and interacts with one of the two phenyl rings on QNB (Fig. 2), differs from all other muscarinic receptor subtypes which have leucine in the homologous position. The importance of $\mathrm{Asp}^{3.32}$ for both agonist and antagonist binding has been demonstrated in mutagenesis and covalent-labeling experiments and modeling studies ${ }^{19-22}$. In contrast, mutation of $A s n 404^{6.52}$ to Ala on $\mathrm{M}_{1}{ }^{23}$ and $\mathrm{M}_{3}{ }^{24}$ receptors was shown to greatly affect binding of QNB but have little effect on binding of or activation by acetylcholine. It is possible that Asn $404^{6.52}$ is hydrogen-bonded with ester group of QNB but not of acetylcholine.

The $M_{2}$ and other muscarinic receptors represent one of four families of acetylcholine binding proteins to be structurally characterized thus far. Figure $3 a$ shows the orthosteric binding site of the $M_{2}$ receptor with acetylcholine docked with the gauche form of the O-C2-C1-N dihedral angle, which places the choline group in the aromatic cage interacting with Asp $103^{3.32}$, while the carbonyl oxygen is tentatively bound to Asn404 ${ }^{6.52}$ (Fig 3a). The natural agonist acetylcholine is much smaller than the bulky antagonist QNB. As described in agonist-bound structure of the $\beta_{2}$ adrenergic receptor, the contraction of ligand binding pocket is expected as a result of an inward shift of $\mathrm{TM}^{25}$. This result is consistent with the previous mutation studies showing that Thr $187^{5.39}$ and Thr $190^{5.42}$ in TM5 (Fig. 2) alter binding of most agonists but not of antagonists ${ }^{20}$. Bulky compounds capable 
of blocking activation-related contraction of the pocket would be very efficient in locking $\mathrm{M}_{2}$ receptor in an inactive conformation as is exemplified here by the antagonist QNB. It has been proposed that the conformational change of $\mathrm{M}_{2}$ receptor upon activation might be accompanied by conformational change of acetylcholine from the gauche to trans form of the O-C2-C1-N dihedral angle ${ }^{26}$. It remains to be determined in which pose acetylcholine binds to the $M_{2}$ receptor or to the $M_{2}$ receptor-G protein complex, and if acetylcholine hydrogen bonds with Asn $404^{6.52}$ or other residues.

In a striking example of convergent evolution, the orthosteric site of $\mathrm{M}_{2}$ receptor exhibits many features noted previously as common structural elements in unrelated acetylcholine binding proteins ${ }^{27}$. Like the $M_{2}$ receptor, a nicotinic acetylcholine receptor homologue bound to acetylcholine (Fig. 3b) shows an aromatic cage comprised of three tyrosines and a tryptophan, although it notably lacks a counterion to the choline group ${ }^{28}$, whereas in the $\mathrm{M}_{2}$ receptor this role is filled by $A s p 103^{3.32}$. A bacterial acetylcholine binding protein ChoX from Sinorhizobium meliloti (Fig. 3c) also possesses an aromatic cage, and like $\mathrm{M}_{2}$ receptor has an aspartate in close proximity to the amine engaging in a chargecharge interaction ${ }^{29}$. Also like the $\mathrm{M}_{2}$ receptor, ChoX has an asparagine hydrogen bonding to the ligand carbonyl. Like these proteins, the enzyme acetylcholine esterase (Fig. 3d) employs an aromatic cage and a carboxylate to bind the choline group, while the (thio)acetyl group interacts with a phenylalanine, likely through $\pi-\pi$ interactions ${ }^{30}$. Taken together, these structures suggest that an aromatic cage and buried carboxylate are likely to be critical elements for acetylcholine recognition and binding in general.

There is a growing interest in the development of allosteric ligands for GPCR targets. This is motivated by the ability to develop more subtype-selective drugs targeted at less conserved regions of the receptor. Moreover, allosteric ligands modulate the effects of natural hormones and neurotransmitters, and may therefore regulate receptor activity in a more physiologic manner. As noted 
above, the orthosteric binding pocket is highly conserved among all muscarinic receptor subtypes. Allosteric regulation of GPCRs was first observed for the $M_{2}$ receptor and this receptor has been one of the most extensively characterized allosteric model systems ${ }^{9}$. Figure $4 a$ shows the inner surface of the $M_{2}$ receptor highlighting residues that are not conserved with its closest relative, the $M_{4}$ receptor. It can be seen that the orthosteric binding pocket and transmembrane core are highly conserved. The greatest diversity is observed in the extracellular loops and the extracellular end of TM segments that form the entrance to the orthosteric binding pocket. These amino acids represent structural diversity that could be exploited for the development of more subtype-selective ligands ${ }^{9}$. Of interest, site-directed mutagenesis and chimeric receptor studies have implicated several of these amino acids in the binding of several well-characterized allosteric modulators ${ }^{9}$. As shown in Fig $4 b-d$, these residues are located in ECL2 and N-terminus of TM7 at the entrance to the binding pocket. Trp422 ${ }^{7.35}$, a residue implicated in the binding of several allosteric modulators, appears to form an edge-to-face $\pi-\pi$ interaction with $T y r 403^{6.51}$, part of the aromatic cage surrounding the charged amine of the orthosteric ligand (Fig. 4d). Binding of allosteric ligands to this site would be expected to influence the association and disassociation rates of orthosteric ligands.

The structure of the $M_{2}$ receptor provides insights into both orthosteric and allosteric regulation of muscarinic receptors. The development of more selective drugs for muscarinic receptors will likely require exploitation of the more diverse allosteric surface, either as exclusively allosteric ligands or as ligands that occupy both orthosteric and allosteric sites.

\section{Methods summary}

Untagged human $\mathrm{M}_{2}$ muscarinic acetylcholine receptor was expressed in Sf9 cells with the third intracellular loop replaced with T4 lysozyme, then extracted with digitonin and sodium cholate and purified by ligand affinity chromatography, then exchanged into decyl maltoside buffer. Purified receptor was crystallized by 
the lipidic cubic phase technique following addition of a stabilizing neopentyl glycol detergent. Data collection was performed at Advanced Photon Source beamlines 23ID-B and 23ID-D, and the structure solved by molecular replacement. Refinement statistics are given in Supplementary Table 2. 


\section{Literature Cited}

1. Hulme, E. C., Birdsall, N. J. \& Buckley, N. J. Muscarinic receptor subtypes. Annu. Rev. Pharmacol. and Toxicol. 30, 633-673, (1990).

2. Dale, H. H. The action of certain esters and ethers of choline, and their relation to muscarine. J. Pharmacol. Exp. Ther. 6, 147-190 (1914).

3. Haga, K. et al. Functional reconstitution of purified muscarinic receptors and inhibitory guanine nucleotide regulatory protein. Nature 316, 731-733 (1985).

4. Haga, K. \& Haga, T. Purification of the muscarinic acetylcholine receptor from porcine brain. J. Biol. Chem. 260, 7927-7935 (1985).

5. Kubo, T. et al. Cloning, sequencing and expression of complementary DNA encoding the muscarinic acetylcholine receptor. Nature 323, 411-416 (1986).

6. Dixon, R. A. et al. Cloning of the gene and cDNA for mammalian betaadrenergic receptor and homology with rhodopsin. Nature 321, 75-79 (1986).

7. Ovchinnikov Yu, A. Rhodopsin and bacteriorhodopsin: structure-function relationships. FEBS letters 148, 179-191 (1982).

8. Wess, J., Eglen, R. M. \& Gautam, D. Muscarinic acetylcholine receptors: mutant mice provide new insights for drug development. Nat. Rev. Drug Discovery 6, 721-733 (2007).

9. Gregory, K. J., Sexton, P. M. \& Christopoulos, A. Allosteric modulation of muscarinic acetylcholine receptors. Curr. Neuropharmacol. 5, 157-167 (2007).

10. Kameyama, K., Haga, K., Haga, T., Moro, O. \& Sadée, W. Activation of a GTP-binding protein and a GTP-binding-protein-coupled receptor kinase (beta-adrenergic-receptor kinase-1) by a muscarinic receptor $\mathrm{m}_{2}$ mutant lacking phosphorylation sites. Eur. J. Biochem. / FEBS 226, 267-276 (1994).

11. Ichiyama, S. et al. The structure of the third intracellular loop of the muscarinic acetylcholine receptor $\mathrm{M}_{2}$ subtype. FEBS Lett. 580, 23-26 (2006).

12. Rosenbaum, D. M. et al. GPCR engineering yields high-resolution structural insights into $\beta_{2}$-adrenergic receptor function. Science 318, 12661273 (2007).

13. Jaakola, V. P. et al. The 2.6 angstrom crystal structure of a human $A_{2 A}$ adenosine receptor bound to an antagonist. Science 322, 1211-1217 (2008).

14. Wu, B. et al. Structures of the CXCR4 chemokine GPCR with smallmolecule and cyclic peptide antagonists. Science 330, 1066-1071 (2010).

15. Chien, E. Y. et al. Structure of the human dopamine D3 receptor in complex with a D2/D3 selective antagonist. Science 330, 1091-1095 (2010).

16. Shimamura, $\mathrm{T}$. et al. Structure of the human histamine $\mathrm{H}_{1}$ receptor complex with doxepin. Nature 475, 65-70 (2011).

17. Palczewski, K. et al. Crystal structure of rhodopsin: A G protein-coupled 
receptor. Science 289, 739-745 (2000).

18. Warne, $\mathrm{T}$. et al. Structure of a $\beta_{1}$-adrenergic G-protein-coupled receptor. Nature 454, 486-491 (2008).

19. Hulme, E. C., Lu, Z. L. \& Bee, M. S. Scanning mutagenesis studies of the $\mathrm{M}_{1}$ muscarinic acetylcholine receptor. Recept. Channels 9, 215-228 (2003).

20. Heitz, F. et al. Site-directed mutagenesis of the putative human muscarinic $\mathrm{M}_{2}$ receptor binding site. Eur. J. Pharmacol. 380, 183-195 (1999).

21. Wess, J. Mutational analysis of muscarinic acetylcholine receptors: structural basis of ligand/receptor/G protein interactions. Life Sci. 53, 1447-1463 (1993).

22. Goodwin, J. A., Hulme, E. C., Langmead, C. J. \& Tehan, B. G. Roof and floor of the muscarinic binding pocket: variations in the binding modes of orthosteric ligands. Mol. Pharmacol. 72, 1484-1496 (2007).

23. Ward, S. D., Curtis, C. A. \& Hulme, E. C. Alanine-scanning mutagenesis of transmembrane domain 6 of the $M_{1}$ muscarinic acetylcholine receptor suggests that Tyr381 plays key roles in receptor function. Mol. Pharmacol. 56, 1031-1041 (1999).

24. Bluml, K., Mutschler, E. \& Wess, J. Functional role in ligand binding and receptor activation of an asparagine residue present in the sixth transmembrane domain of all muscarinic acetylcholine receptors. J. Biol. Chem. 269, 18870-18876 (1994).

25. Rasmussen, S. G. et al. Structure of a nanobody-stabilized active state of the $\beta_{2}$ adrenoceptor. Nature 469, 175-180 (2011).

26. Furukawa, $\mathrm{H}$. et al. Conformation of ligands bound to the muscarinic acetylcholine receptor. Mol. Pharmacol. 62, 778-787 (2002).

27. Zacharias, N. \& Dougherty, D. A. Cation- $\pi$ interactions in ligand recognition and catalysis. Trends Pharmacol. Sci. 23, 281-287, (2002).

28. Brams, M. et al. Crystal structures of a cysteine-modified mutant in loop D of acetylcholine-binding protein. J. Bio.I Chem. 286, 4420-4428, (2011).

29. Oswald, C. et al. Crystal structures of the choline/acetylcholine substratebinding protein ChoX from Sinorhizobium meliloti in the liganded and unliganded-closed states. J. Biol. Chem. 283, 32848-32859, (2008).

30. Colletier, J. P. et al. Structural insights into substrate traffic and inhibition in acetylcholinesterase. EMBO J. 25, 2746-2756 (2006).

Supplementary Information is linked to the online version of the paper at www.nature.com/nature.

Acknowledgements We thank Prof. So Iwata at Kyoto University for supporting the production of $\mathrm{M}_{2}$ receptor, and we acknowledge support from the Japan 
Society for the Promotion of Science (Research for Future Program)(T.H.), from the Japan Science and Technology Corporation (CREST) (T.H.), from the Ministry of Education, Culture, Sports, Science, and Technology of Japan (Grants-in-Aid for Scientific Research on Priority Area 15083201 (T.H.), from the Japan Science and Technology Corporation (ERATO) (T.K.), from Toray Science Foundation (T.K.), from Takeda Science Foundation (T.K.), from Ichiro Kanehara Foundation (T.K.), from The Sumitomo Foundation (T.K.), from the National Institutes of Health Grants NS028471 and GM083118 (B.K.K), from the Mathers Foundation (B.K.K. and W.I.W.), and from the National Science Foundation (A.C.K.). We thank Tong Sun Kobilka for organizing the GPCR Workshop 2010 that brought together the research groups, and for facilitating this collaboration.

Author Contributions K.H. purified $\mathrm{M}_{2}$ and $\mathrm{M}_{2}-\mathrm{T} 4 \mathrm{~L}$ receptors, characterized their ligand binding activity, and performed attempts to crystallize them with hanging drop and other methods for more than ten years. A.C.K. crystallized the $\mathrm{M}_{2}-\mathrm{T} 4 \mathrm{~L}$ in lipidic cubic phase, collected and processed diffraction data, solved and refined the structure, and assisted with manuscript preparation. H.A. set up the expression system and expressed $\mathrm{M}_{2}$-T4L for in large amounts using the insect cell/baculovirus expression system. T.Y-K. has expressed using a yeast expression system, and has purified and crystallized $M_{2}$ and $M_{2}-T 4 L$ receptors for five years. M.S. constructed several mutants of $\mathrm{M}_{2}-\mathrm{T} 4 \mathrm{~L}$ and evaluated their stabilities. C.Z. assisted with data collection and processing. W.I.W. oversaw data processing and refinement. T.O. gave advice to K.H. and T.H. on crystallization of the $\mathrm{M}_{2}$ receptor and interpretation of its structure. B.K. oversaw lipidic cubic phase crystallization, assisted with data collection, and wrote the manuscript together with T.H. and T.K. T.H., together with K.H., has engaged in biochemical studies of muscarinic receptors for more than thirty years, prepared $\mathrm{M}_{2}$ and $\mathrm{M}_{2}$ T4L receptors, and wrote a part of manuscript. T.K. has been collaborating with T.H. for five years, designed the receptor production strategy with T.H., and wrote a part of manuscript. 
Author Information Coordinates and structure factors for M2-T4L are deposited in the Protein Data Bank (accession code 3UON). Reprints and permission information is available at www.nature.com/reprints. The authors declare no competing financial interests. Readers are welcome to comment on the online version of this article at www.nature.com/nature. Correspondence and requests for materials should be addressed to B.K.K. (kobilka@stanford.edu), T.H. (tatsuya.haga@gakushuin.ac.jp), or T.K. (t-coba@mfour.med.kyoto-u.ac.jp). 


\section{Figure Legends}

Figure 1. The $M_{2}$ receptor (blue ribbon) with bound QNB (orange spheres). a, $M_{2}$ receptor in profile. $\mathbf{b}$, Cytoplasmic surface showing conserved DRY residues in TM3. c, Extracellular view into QNB binding pocket. d, Extracellular view with solvent-accessible surface rendering shows a funnel-shaped vestibule and a nearly buried QNB binding pocket. e, Aqueous channel (green) extending from the extracellular surface into the transmembrane core is interrupted by a layer of three hydrophobic residues (blue spheres). Well-ordered water molecules are shown as red dots.

Figure 2. Binding interactions between the $M_{2}$ receptor and QNB.

$\mathbf{a}, \mathbf{b}$, Two views of the QNB binding pocket. Amino acids within $4 \AA$ of the ligand are shown as light blue sticks, with QNB in orange. Nitrogen and oxygen atoms are colored dark blue and red, respectively. Polar interactions are indicated by dashed lines. $A 2 F_{o}-F_{c}$ map is shown in wire at $1.5 \sigma$ contour. $c$, A schematic representation of QNB binding interactions is shown. Mutations of amino acids in red boxes have been shown to reduce both antagonist and agonist binding by more than 10 fold. Mutations of the amino acid in the purple boxes reduce antagonist binding affinity by more that 10 fold. Mutations of amino acids in blue boxes reduce agonist binding by more than 10 fold. Blue dotted lines indicate potential hydrophobic interactions and red lines indicate potential polar interactions.

Figure 3. Convergent evolution of acetylcholine binding sites. a, Acetylcholine is modeled into the crystal structure of the $M_{2}$ receptor. $\mathbf{b}$, Acetylcholine binding pocket in the crystal structure of the acetylcholine binding protein from the snail Aplysia californica (PDB ID: 2XZ5). c, Acetylcholine binding pocket in the acetylcholine binding protein ChoX from the gram negative bacterium Sinorhizobium meliloti (PDB ID: 2RIN). d, Binding site for thio-acetylcholine in the enzyme acetylcholine esterase from the electric ray Torpedo californica (PDB ID: $2 \mathrm{C} 4 \mathrm{H})$. 
Figure 4. Allosteric binding in the $M_{2}$ receptor. a, Differences between the $M_{2}$ and $M_{4}$ receptors are shown as green residues mapped onto the inner surface of the $M_{2}$ receptor (blue), with QNB in orange spheres. The sequence conservation within the orthosteric site is apparent, while residues outside show more variability. b-d, Mutations that alter allosteric binding are shown with yellow carbons, and amino acids involved in QNB binding are shown with blue carbons as sticks or spheres. b, c, Different views of possible allosteric binding sites in the $M_{2}$ receptor. The surface view in $\mathbf{c}$ shows the positions of possible allosteric binding sites (yellow) lining the path to the QNB binding pocket. d, Trp422 (yellow spheres), implicated in binding of allosteric ligands, forms an edge-to-face aromatic interaction with Tyr403, part of the aromatic cage (blue spheres) of the orthosteric site. 


\section{Methods}

\section{Construction of $\mathrm{M}_{2}-\mathrm{T} 4 \mathrm{~L}$ expression vectors for Sf9 cells}

The coding sequence of the human $\mathrm{M}_{2}-\mathrm{T} 4 \mathrm{~L}$ was designed to have $\mathrm{N}$-linked glycosylation sites (Asn2, Asn3, Asn6 and Asn9) mutated to aspartic acid and cysteine-less T4 lysozyme (C54T, C97A) residues 2 - 161 inserted into the third intracellular loop, replacing $M_{2}$ residues 218 - 376. This construct was synthesized (TAKARA bio Inc.), and cloned into the pFastbac1 Sf9 expression vector (Invitrogen) as illustrated in Supplementary Figure 1a. A TAA stop codon was placed after the R466 codon, terminating translation. The synthesized $\mathrm{M}_{2}-$ $\mathrm{T} 4 \mathrm{~L}$ described above was confirmed by sequencing.

\section{Expression and membrane preparation}

Recombinant baculovirus was made from pFastbac1- $\mathrm{M}_{2}-\mathrm{T} 4 \mathrm{~L}$ using the Bac-toBac system (Invitrogen) ${ }^{31}$. The $\mathrm{M}_{2}-\mathrm{T} 4 \mathrm{~L}$ protein was expressed in baculovirus infected Sf9 insect cell as described previously ${ }^{32}$. Sf9 insect cells were prepared at a density of $1.0 \times 10^{6}$ cells $/ \mathrm{ml}$ and suspended in $5 \mathrm{~L}$ of the IPL-41/SF900 II complex media or ESF921 insect media. Media containing Sf9 insect cells were transferred into the CELLBAG 22 L/O (GE Healthcare) and cultured for 4 days with the following culture conditions: $20 \mathrm{rpm}, 8.5^{\circ}$ of rocking angle, $30 \% \mathrm{O}_{2}, 0.25$ $\mathrm{L} / \mathrm{min}$ of air flow rate, and $27^{\circ} \mathrm{C}$. After 4 days, $200 \sim 300 \mathrm{ml}$ of the $\mathrm{M}_{2}-\mathrm{T} 4 \mathrm{~L}$ baculovirus stock (approximate multiplicity of infection (M.O.I) $=2$ ) and 700 800 $\mathrm{ml}$ of IPL-41/SF900 II complex media were transferred into the CELLBAG (final culture volume $=6 \mathrm{~L}$ ) and infected for 2 days under the following infection conditions: $22 \mathrm{rpm}, 8.5^{\circ}$ of rocking angle, $50 \% \mathrm{O}_{2}$, air flow rate, $0.25 \mathrm{~L} / \mathrm{min}$, and $27^{\circ} \mathrm{C}$. Two days later, a fraction of the cells was harvested for the binding assay and the remaining cells were centrifuged at $6,000 \times \mathrm{g}$ for $10 \mathrm{~min}$ and harvested. The cell pellet was washed with $250 \mathrm{ml}$ of Phosphate Buffered Saline without calcium chloride and magnesium chloride (PBS(-)) and resuspended with $100 \mathrm{ml}$ of PBS(-) containing a protease inhibitor cocktail tablet (Roche). Final concentration of protease inhibitors was $2.5 \mu \mathrm{g} / \mathrm{ml}$ pepstatin, $2 \mu \mathrm{g} / \mathrm{ml}$ PMSF, 20 
$\mu \mathrm{g} / \mathrm{ml}$ leupeptin, and $0.5 \mathrm{mM}$ benzamidine. Cells were quick frozen in liquid nitrogen and stored at $-80^{\circ} \mathrm{C}$.

The membrane was prepared from the $\mathrm{M}_{2}-\mathrm{T} 4 \mathrm{~L}$ expressing Sf9 insect cells as described previously ${ }^{31}$. For the preparation of membranes from insect cells, Sf9 insect cells were centrifuged at $1,500 \mathrm{~g}$ for $10 \mathrm{~min}$ at $4^{\circ} \mathrm{C}$. The pellet was washed with PBS(-), then resuspended in $100 \mathrm{ml}$ of hypotonic buffer containing $10 \mathrm{mM}$ HEPES at $\mathrm{pH} 7.5,20 \mathrm{mM} \mathrm{KCl}, 10 \mathrm{mM} \mathrm{MgCl}_{2}$, and protease inhibitor cocktail, followed by Dounce homogenization to resuspend the membranes. Insect cell membranes were centrifuged at $100,000 \mathrm{~g}$ for $30 \mathrm{~min}$ and the pellets were resuspended in $10 \mathrm{mM}$ HEPES at $\mathrm{pH} 7.5,10 \mathrm{mM} \mathrm{MgCl}_{2}, 20 \mathrm{mM} \mathrm{KCl}, 40 \%$ glycerol, and snap-frozen in liquid nitrogen and then stored at $-80^{\circ} \mathrm{C}$ until use. Membrane proteins were quantified using the bicinchoninic acid (BCA) method (Pierce) using a BSA standard.

\section{Purification of $\mathrm{M}_{2}-\mathrm{T} 4 \mathrm{~L}-\mathrm{QNB}$}

$\mathrm{M}_{2}-\mathrm{T} 4 \mathrm{~L}$ was expressed in Sf9 cells, solubilized with digitonin/Na-cholate solution, and purified by using an affinity column with aminobenztropine (ABT) as a ligand ${ }^{33}$, as described below. The whole procedure was carried out at $4^{\circ} \mathrm{C}$. Sf9 membrane preparations with $2.1 \mathrm{~kg}$ of wet weight and approximately $1.5 \mu \mathrm{mol}$ of $\left[{ }^{3} \mathrm{H}\right]$ QNB binding sites were solubilized with $1 \%$ digitonin/0.35\% Na-cholate/10 $\mathrm{mM}$ K-phosphate buffer ( $\mathrm{pH} 7.0)(\mathrm{KPB}) / 50 \mathrm{mM} \mathrm{NaCl} / 1 \mathrm{mM}$ EDTA/a cocktail of protease inhibitors $(4 \mathrm{~L})$. The supernatant was applied to two ABT-columns run in parallel $(500 \mathrm{ml}$ each), followed by washing with $0.1 \%$ digitonin $/ 0.1 \% \mathrm{Na}$ cholate/20 mM KPB/150 mM NaCl $(2 \mathrm{~L} \times 2)$ at a rate of approximately $90 \mathrm{ml} / \mathrm{hr}$. $\mathrm{M}_{2}-\mathrm{T} 4 \mathrm{~L}$ was eluted from the ABT columns with $0.5 \mathrm{mM}$ atropine/0.1\% digitonin/0.1\% Na-cholate/20 mM KPB/150mM NaCl in $2 \mathrm{~L}$ elution volume for each column, and was bound to a column of hydroxyapatite $(30 \mathrm{ml})$, which was washed at a rate of $30-50 \mathrm{ml} / \mathrm{hr}$ with a series of solutions as follows (1) $0.1 \%$ digitonin/0.1\% Na-cholate/20 mM KPB (100 ml), (2) $5 \mu \mathrm{M}$ QNB/ $0.1 \%$ digitonin/0.1\% Na-cholate/20 mM KPB (600 ml), (3) 0.35\% Na-cholate/20 mM 
KPB (600 ml), (4) $0.2 \%$ decylmaltoside $/ 20 \mathrm{mM} \mathrm{KPB} \mathrm{(500} \mathrm{ml),} \mathrm{(5)} 0.2 \%$ decylmaltoside/150 mM KPB (100 ml), (6) 0.2\% decylmaltoside/500 mM KPB (60 $\mathrm{ml}$ ). $\mathrm{M}_{2}$-T4L-QNB was finally eluted with $0.2 \%$ decylmaltoside/1 $\mathrm{M} \mathrm{KPB}(50 \mathrm{ml})$. The eluate was concentrated to approximately $1 \mathrm{ml}$ (ca $30 \mathrm{mg}$ protein/ml) with Amicon Ultra (MILLIPORE), followed by dialysis against $0.2 \%$ decylmaltoside/20 $\mathrm{mM}$ Tris- $\mathrm{HCl}$ buffer $\left(\mathrm{pH} \mathrm{7.5)}\right.$ and storage in $-80^{\circ} \mathrm{C}$. The yield was estimated to be approximately $50 \%$ on the assumption that the recovered protein is pure $\mathrm{M}_{2}$ T4L. Protein concentration was determined using BCA Protein Assay (PIERCE). Since we purified $\mathrm{M}_{2}-\mathrm{T} 4 \mathrm{~L}$ as a complex with QNB we could not estimate the $\left[{ }^{3} \mathrm{H}\right]$ QNB binding activity because the dissociation rate of QNB is too slow. However, in preliminary experiments using $\left[{ }^{3} \mathrm{H}\right] \mathrm{QNB}$ or dissociable atropine as eluants, we confirmed that the receptor is purified to near homogeneity. The purity of $\mathrm{M}_{2}-\mathrm{T} 4 \mathrm{~L}$ was confirmed by SDS-PAGE and gel permeation chromatography (Supplementary Fig. 6). All QNB used in purification and crystallization was the high affinity enantiomer, R-(-)-3-QNB.

\section{Measurement of ligand binding activity}

Ligand binding activity of wild type $\mathrm{M}_{2}$ and $\mathrm{M}_{2}-\mathrm{T} 4 \mathrm{~L}$ receptors was determined as described previously ${ }^{34}$. Briefly, the receptors solubilized from Sf9 membranes were incubated with $0.1-4 \mathrm{nM}\left[{ }^{3} \mathrm{H}\right] \mathrm{QNB}$ with or without $1 \mu \mathrm{M}$ atropine, or with 2 $n M\left[{ }^{3} \mathrm{H}\right] \mathrm{QNB}$ with various concentrations of carbamylcholine or atropine in $0.1 \%$ digitonin/20 mM KPB for $60 \mathrm{~min}$ at $30^{\circ} \mathrm{C}$ (total volume $0.2 \mathrm{ml}$ ). The amount of $\left[{ }^{3} \mathrm{H}\right]$ QNB bound to receptors was assayed by using a small column of Sephadex G50 fine (2 ml). The density of $\left[{ }^{3} \mathrm{H}\right]$ QNB binding sites in particulate fraction of $\mathrm{M}_{2}-$ $\mathrm{T} 4 \mathrm{~L}$ was $17 \mathrm{pmol} / \mathrm{mg}$ of protein in average and ranged from 5.3 to $35 \mathrm{pmol} / \mathrm{mg}$ of total protein.

\section{Crystallization}

QNB-bound $\mathrm{M}_{2}-\mathrm{T} 4 \mathrm{~L}$ was concentrated to $20 \mathrm{mg} / \mathrm{ml}$ in decyl maltoside buffer in a volume of approximately $100 \mu \mathrm{l}$. A $10 \%$ stock solution of lauryl maltose neopentyl glycol detergent (MNG, Anatrace) with $100 \mathrm{mM} \mathrm{NaCl}$ and $20 \mathrm{mM}$ HEPES pH 7.5 
was then added to the protein to a final concentration of $1 \%(\mathrm{w} / \mathrm{v})$ of $\mathrm{MNG}$ detergent. The sample was incubated 1 hour on ice, then diluted to $1 \mathrm{ml}$ in $0.1 \%$ MNG buffer and reconcentrated to $50 \mathrm{mg} / \mathrm{ml}$ prior to reconstitution. The final volume of protein sample at this concentration was typically $20-30 \mu$ l. Protein was reconstituted in cubic phase by mixing with a 1.5-fold weight excess of a 10:1 monoolein:cholesterol mix by the twin-syringe method ${ }^{35}$. Briefly, the protein and lipid were mixed by passage through coupled syringes 100 times either by hand or using a Gryphon LCP robot (Art Robbins Instruments). The reconstituted protein was dispensed using a modified ratchet device (Hamilton) or using the Gryphon LCP robot in $40 \mathrm{nl}$ drops to either 24-well or 96-well glass sandwich plates and overlaid with $0.8 \mu$ l precipitant solution. A single crystallization lead was initially identified using an in-house screen and then optimized. Crystals for data collection were grown in 25 to 35\% PEG 300, $100 \mathrm{mM}$ ammonium phosphate, 2\% 2-Methyl-2,4-pentanediol, 100 mM HEPES pH 7.0 - 7.8. Crystals reached full size and were harvested after $3-4$ days at $20^{\circ} \mathrm{C}$. Typical crystals are shown in supplementary figure 7.

\section{Data collection and processing}

Diffraction data were measured at the Advanced Photon Source beamlines 23 ID-B and 23 ID-D. Several hundred crystals were screened, and a final data set was compiled using diffraction wedges of typically 5 degrees from the 23 most strongly diffracting crystals. Data reduction was performed using HKL2000 ${ }^{36}$. Diffraction quality was very heterogeneous, with some crystals diffracting to $2.3 \AA$ while others failed to diffract past $3.5 \AA$. Among the best crystals, most diffracted to $3.0-2.5 \AA$. Severe radiation damage and anisotropic diffraction resulted in low completeness in higher resolution shells. We report this structure to an overall resolution of $3.0 \AA$. Despite the low completeness in high resolution bins, inclusion of these reflections significantly improved map quality. Highest shell $<|>|<\sigma \mid>$ is relatively low, in large part due to anisotropy of the diffraction. The

final resolution cutoff was chosen on the basis of completeness and $\langle\mid\rangle \mid\langle\sigma \mid\rangle$ in the spherical highest shell, but analysis of average F/oF values along reciprocal 
space axes suggests resolution limits (based on $F / \sigma F>3$ ) of $3.5,2.9$, and $2.7 \AA$ along $a^{*}, b^{*}$, and $c^{*}$, respectively. The real space $c$ axis is normal to the plane of the lipid membrane in the crystal.

\section{Structure solution and refinement}

The structure was solved by molecular replacement using Phaser $^{37,38}$ with the structure of the inactive $\beta_{2}$ adrenergic receptor and T4 lysozyme used as search models (PDB ID: 2RH1). The initial molecular replacement model was further fitted by rigid body refinement followed by simulated annealing and restrained refinement in Phenix ${ }^{39}$. Iterative manual rebuilding and refinement steps were performed with Coot and phenix.refine, respectively. Figures were prepared with PyMOL, and Ramachandran statistics were calculated with MolProbity.

\section{Literature cited}

31. Asada, H. et al. Evaluation of the Pichia pastoris expression system for the production of GPCRs for structural analysis. Microb. Cell Fact. 10, 24, doi:10.1186/1475-2859-10-24 (2011).

32. Weber, W., Weber, E., Geisse, S. \& Memmert, K. Optimisation of protein expression and establishment of the Wave Bioreactor for Baculovirus/insect cell culture. Cytotechnology 38, 77-85 (2002).

33. Haga, K. \& Haga, T. Affinity chromatography of the muscarinic acetylcholine receptor. J. Biol. Chem. 258, 13575-13579 (1983).

34. Haga, T., Haga, K. \& Hulme, E. C. Solubilization, purification and molecular characterization of muscarinic acetylcholine receptors. In Receptor Biochemistry : A Practical Approach, (ed. Hulme, E. C.) 51-78 (Oxford University Press, 1990).

35. Caffrey, M. \& Cherezov, V. Crystallizing membrane proteins using lipidic mesophases. Nat. Protoc. 4, 706-731 (2009).

36. Otwinowski, Z. \& Minor, W. Processing of x-ray diffraction data collected in oscillation mode. Methods Enzymol. 276, 307-326 (1997).

37. McCoy, A. J. Solving structures of protein complexes by molecular replacement with Phaser. Acta Crystallogr. D Biol. Crystallogr. 63, 32-41 (2007).

38. McCoy, A. J. et al. Phaser crystallographic software. J. Appl. Crystallogr. 40, 658-674 (2007).

39. Afonine, P. V., Grosse-Kunstleve, R. W. \& Adams, P. D. A robust bulksolvent correction and anisotropic scaling procedure. Acta Crystallogr. $D$ 
Biol. Crystallogr. 61, 850-855 (2005). 


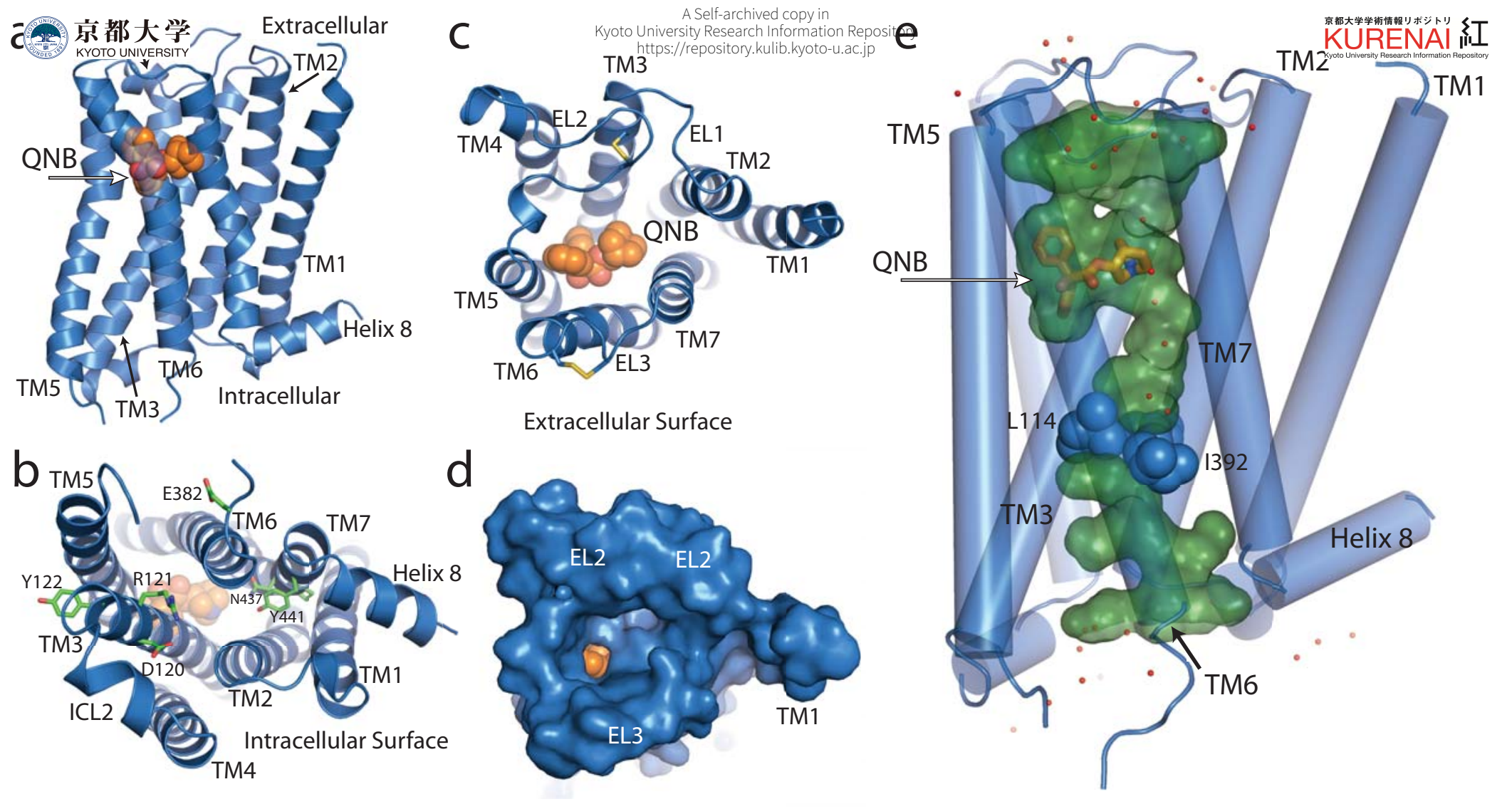


每京都大学

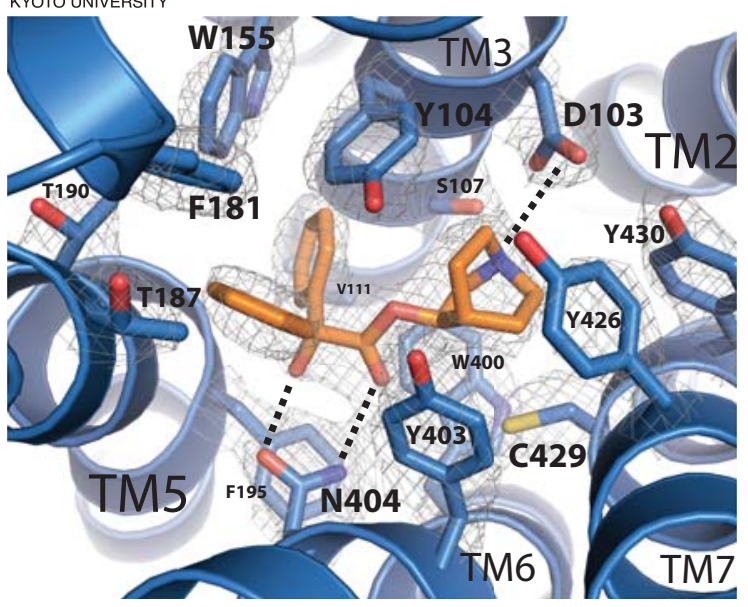

b

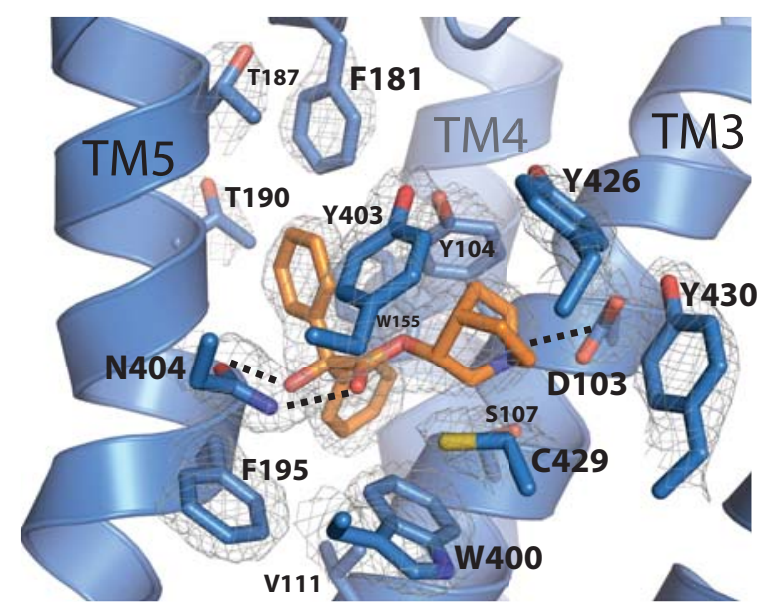

A Self-archived copy in
ersity Research Information Repository

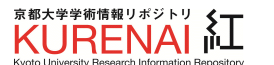

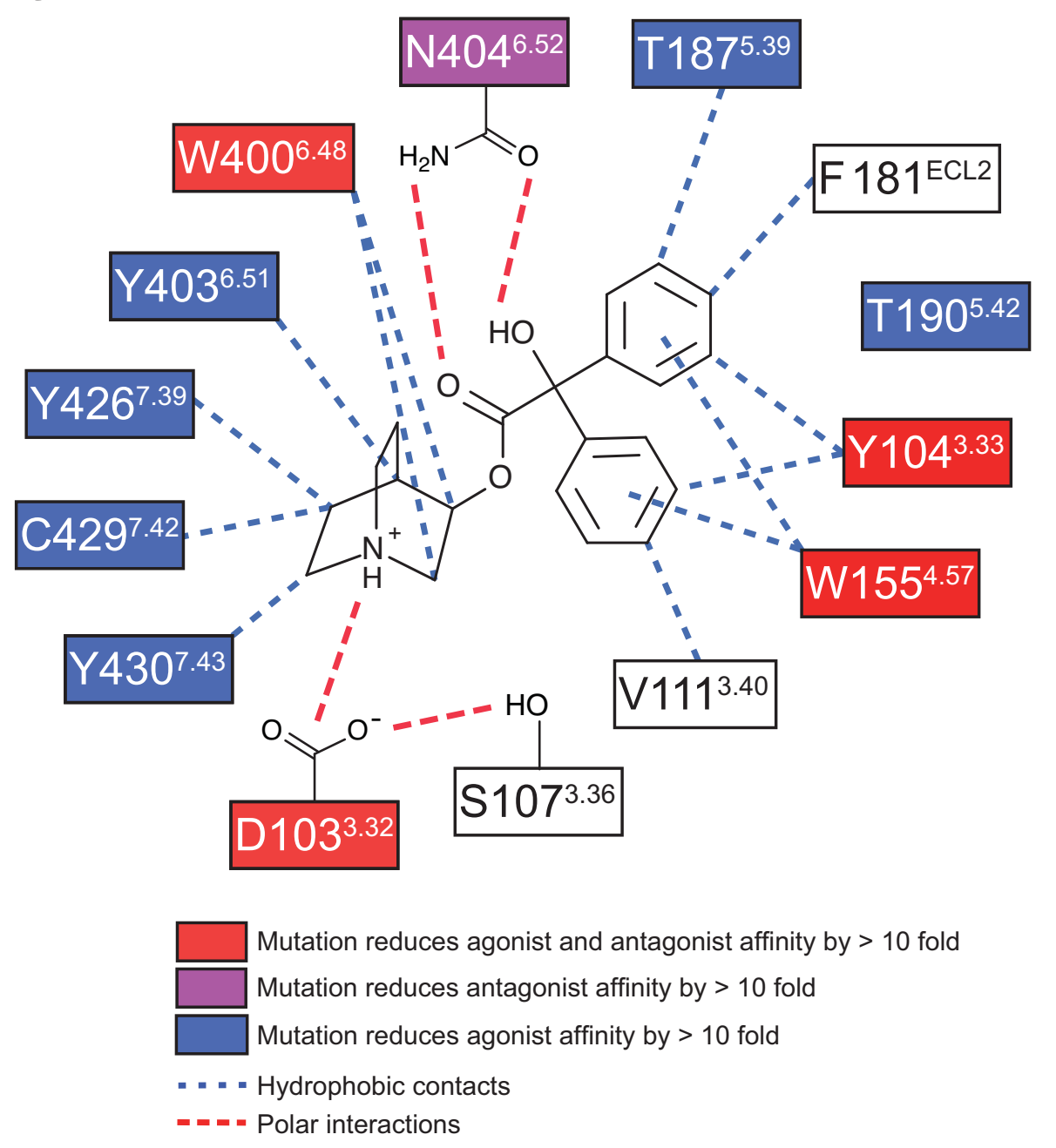


京都大学

hitps:/repository | |b

roto unIVESITYaceptor

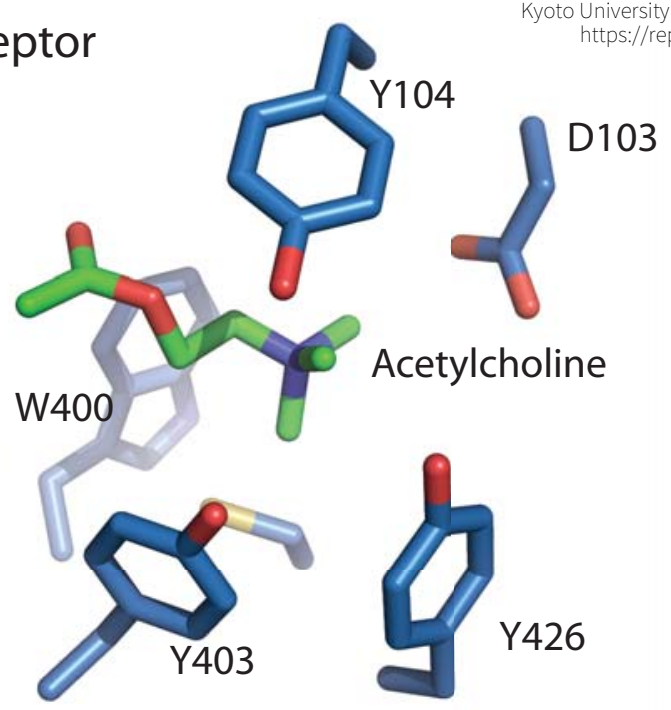

C ChoX protein (bacterium)

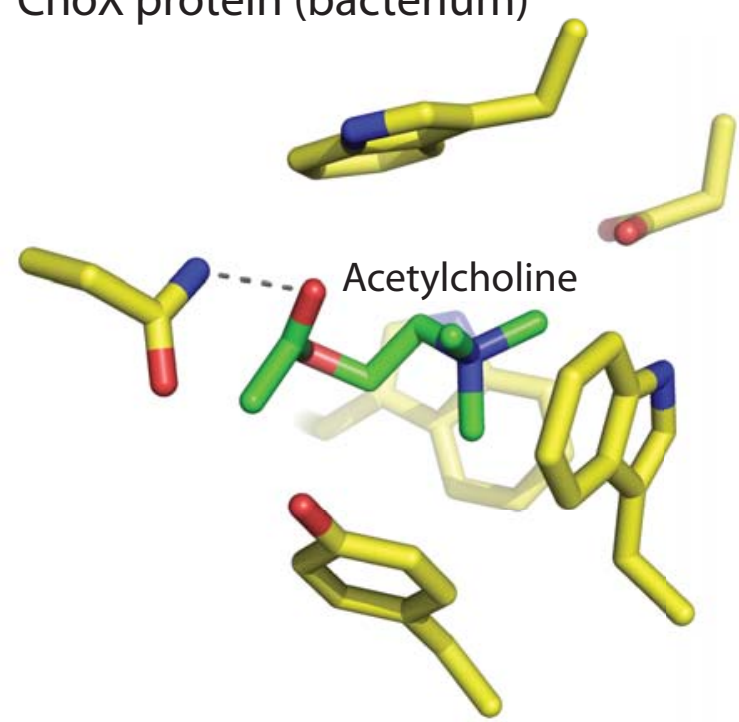

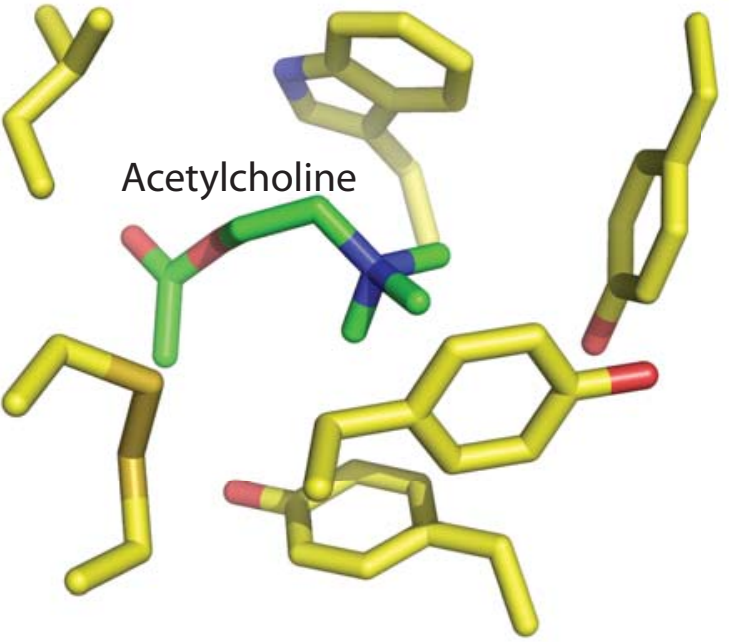

d Acetylcholine esterase (electric ray)
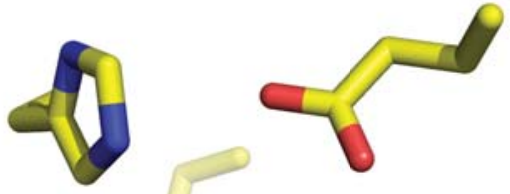

Thioacetylcholine

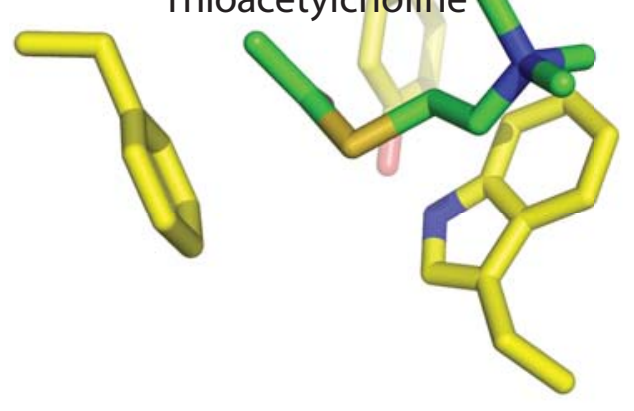<smiles>c1ccccc1</smiles> 
章都大学

A Self-archived copy in
Koret

Kyoto University Research Information Repository

https://repository.kulib.kyoto-u.ac

Extracellular

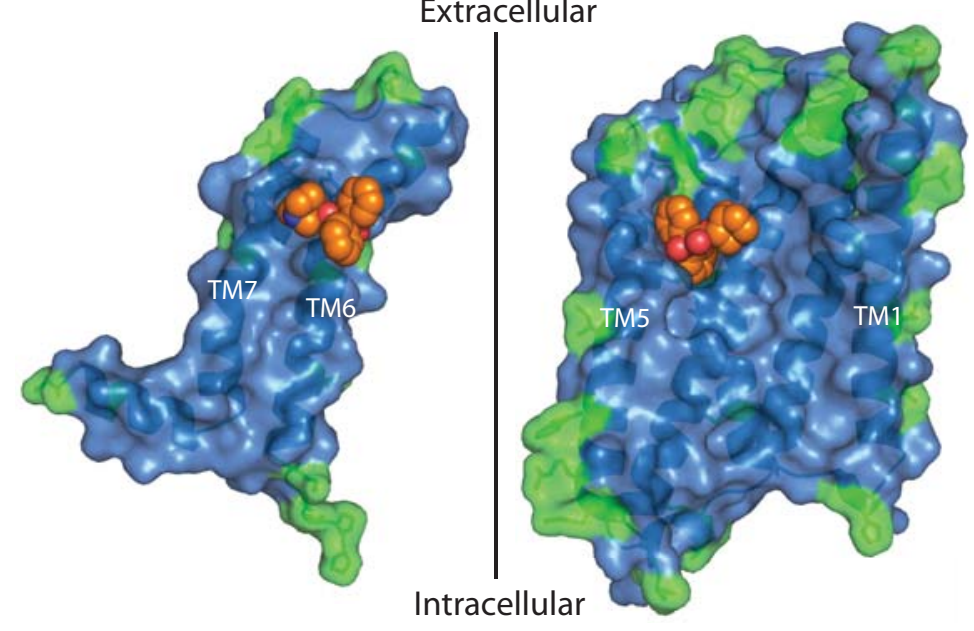

b

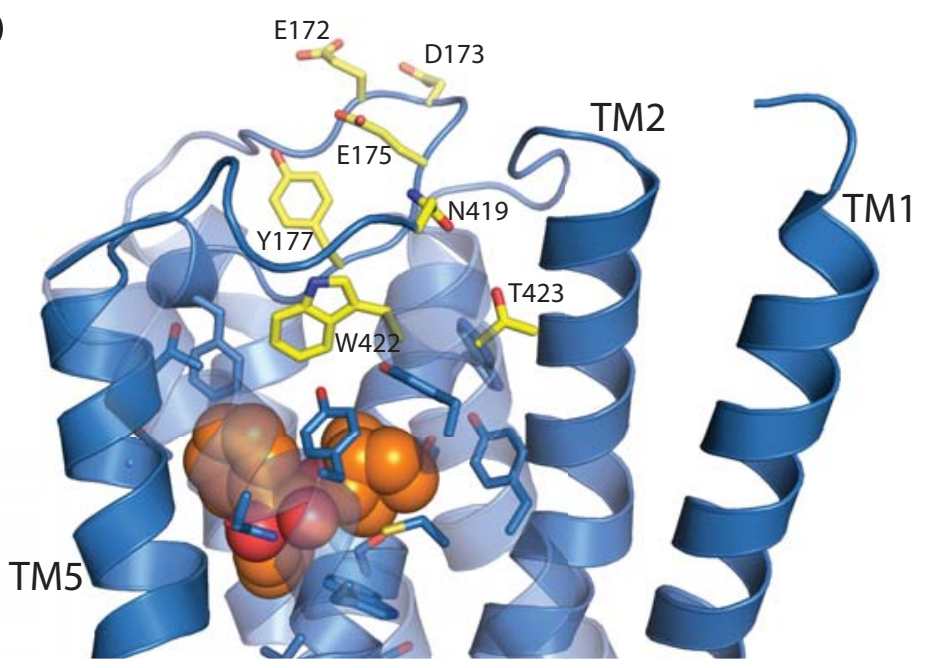

TM3

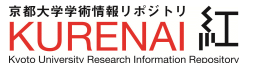
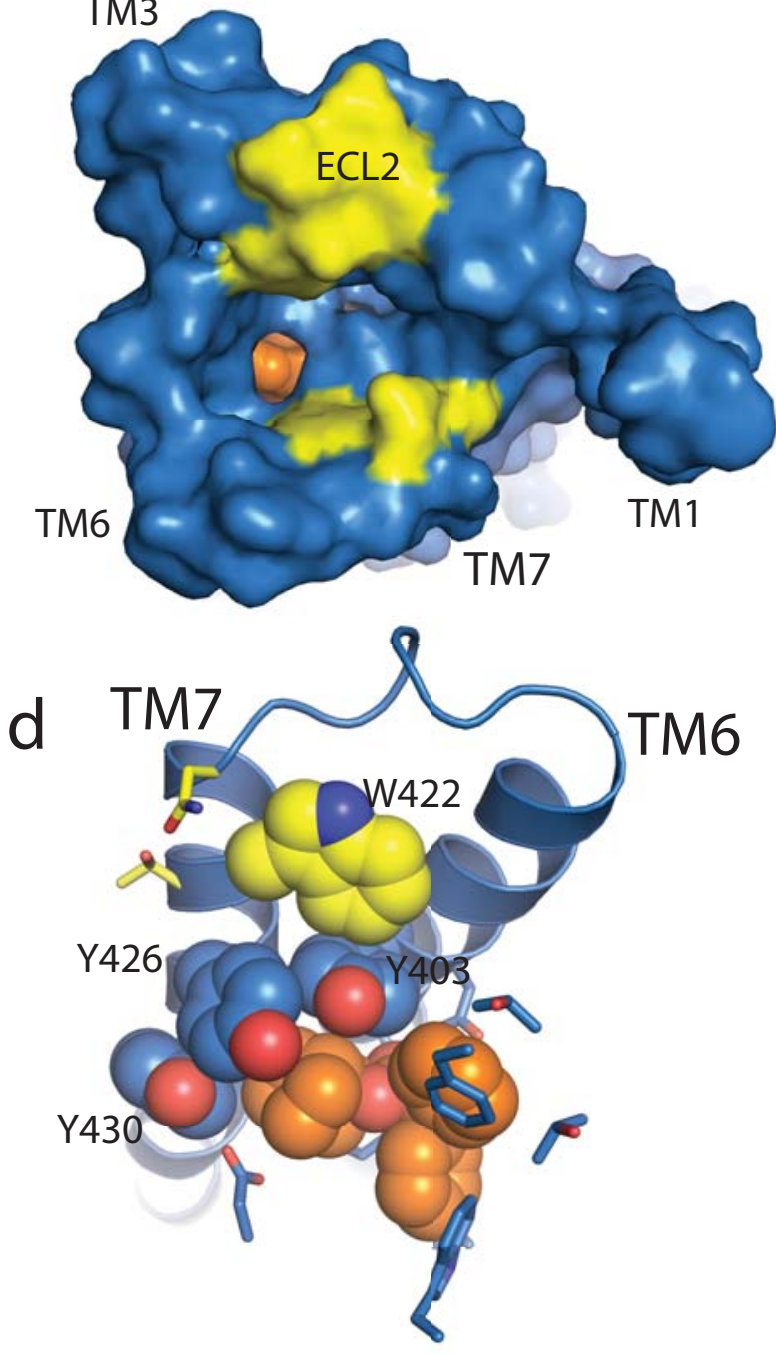